\title{
BIOFUELS FROM COCONUT FAT AND SOYBEAN OIL: MICROWAVE-ASSISTED SYNTHESIS AND GAS CHROMATOGRAPHY/MASS SPECTROMETRY ANALYSIS
}

\author{
Amanda C. Pinheiro, ${ }^{a}$ André B. Gonçalves, ${ }^{a}$ Wilhelm J. Baader, ${ }^{a}$ Lydia F. Yamaguchi, ${ }^{a}$ Naved I. Malek, ${ }^{b}$ Erick L. Bastos, ${ }^{a}$ \\ and Omar A. El Seoud ${ }^{a, *}$

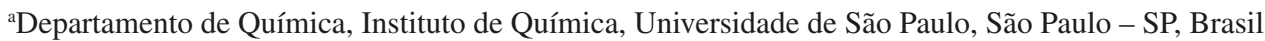 \\ ${ }^{\mathrm{b}}$ Applied Chemistry Department, Sardar Vallabhbhai National Institute of Technology, Surat, Gujarat, India
}

Recebido em 04/02/2018; aceito em 12/06/2018; publicado na web em 21/08/2018

\begin{abstract}
We developed a project during an undergraduate course (advanced experimental chemistry) on the microwave-assisted synthesis of biodiesel (BD), via base-catalyzed transesterification of coconut fat (CF) and soybean oil (SO) by ethanol, followed by product analysis by gas chromatography/mass spectrometry. Our goals were to introduce a problem with relevant socio-economic impact (production of $\mathrm{BD}$ ); to discuss and compare methods for biofuel analysis, and to gain insight into transesterification mechanism as an important example of acyl-transfer reactions. Comparison of both BFs showed clear difference in fatty acid composition; that from CF contains shorter, saturated chains (mainly ethyl dodecanoate- and tetradecanoate), whereas biodiesel from SO is essentially composed of longer unsaturated chains (e.g., ethyl oleate and linoleate). The project takes eight hours to complete, is conceptually simple, being suitable for inclusion in the undergraduate science curriculum.
\end{abstract}

Keywords: upper-division undergraduate; esters; fatty acids; qualitative analysis; quantitative analysis; student-centered learning.

\section{INTRODUCTION}

Biodiesel, BD, designates a non-petroleum based fuel, consisting of alkyl esters of fatty acids derived from biomass. BD is typically produced by acid- or base-catalyzed transesterification of oils and fats from vegetable or animal sources with ethanol or methanol; glycerol is the byproduct. As fuel for diesel (or compression-ignition) engines, BD has several advantages over petroleum-based diesel fuel: it is sulfur-free; depending on the engine its combustion generates between 50 and $78 \%$ less unburned hydrocarbons, $\mathrm{CO}, \mathrm{NO}_{\mathbf{x}}$, particulate matter, and $\mathrm{CO}_{2}$ (due to $\mathrm{CO}_{2}$ fixation during growth of the plants, including sugarcane (source of bioethanol) and soybean (source of vegetable oil).$^{1,2} \mathrm{BD}$ is usually used as blend with diesel oil; the letter "B" followed by a number indicates the volume percent of BD in the blend. In the US and the European Union countries, B15 and B20 are popular (blends with 15 and $20 \mathrm{v} \% \mathrm{BD}$, respectively), because these blends represent good balance of cost, gas emission, and coldweather performance; ${ }^{3}$ in Brazil, B10 is in use since March 2018. ${ }^{4}$

The impetus for introducing BD as a theme in the undergraduate laboratory is its enormous socio-economic importance. In 2016, Brazil was second after the USA, with 3.8 billion liters BD produced. ${ }^{5}$ Additionally, the study of the synthesis, analysis and properties of BD fits within the policy of "education for sustainable development", declared by the United Nations, whose goal is "to integrate the principles, values, and practices of sustainable development into all aspects of education and learning, in order to address the social, economic, cultural, and environmental problems we face in the $21^{\text {st }}$ century" ${ }^{6}$ Consequently, several chemistry education-related papers with different levels of sophistication were published on the subject. These include the synthesis- usually by base-catalyzed transesterification, analysis, and determination of properties of BD from different oils, e.g., spent coffee grounds, ${ }^{7}$ soybean, ${ }^{8,9}$ assorted oils, ${ }^{10,11}$ as well as directly from seeds (soybean, safflower, flaks, and sunflower). ${ }^{12}$ Reviews on different aspects of BD were published, including the mechanism and strategies of transesterification of vegetable oils, ${ }^{13-15}$

\footnotetext{
*e-mail: elseoud.usp@gmail.com
}

economic and regulatory aspects, ${ }^{16}$ evaluation of vegetable oils proper and their alkyl esters as biofuels, ${ }^{17}$ and analyses of BDs. ${ }^{18}$

We introduced a project on BD in Chem-1405 (advanced experimental chemistry) to our third-year chemistry majors (37 students). The emphasis was on the synthesis and composition analysis of BD from coconut fat (CF) and soybean oil (SO). These particular BD sources were chosen because - worldwide - Brazil is the second producer of soybean grain, ${ }^{19}$ and the fourth in both soybean oil and coconut production..$^{20} \mathrm{An}$ important characteristic of $\mathrm{CF}$ is that it is composed of essentially saturated fatty acids, dodecanoic and tetradecanoic acids are dominant, $>60 \%$. On the other hand, the fatty acids of SO are essentially unsaturated; oleic- (9Z)-octadecenoic) and linoleic $(9 Z, 12 Z)$-octadecadienoic) acids are dominant, $>70 \% .^{21,22}$ Consequently, $\mathrm{CF}$ is much less prone to oxidation during deep-frying than $\mathrm{SO}{ }^{23}$ it is used in Brazil for this (cooking) purpose.

The experimental part of the project included microwave (MW)-assisted, base-catalyzed transesterification of CF and SO with sodium ethoxide/ethanol, followed by analysis of the resulting biofuels (mixtures of fatty acid ethyl esters) by gas chromatography/ mass spectrometry (CG/MS). Student contact with this "real-world" problem combines reaction mechanism, product analysis by tandem techniques, ${ }^{24,25}$ and process economy.

\section{EXPERIMENTAL OVERVIEW}

\section{Solvents, reagents, and fatty material}

Chemicals were purchased from Merck and Synth (São Paulo); fatty acids ( $>99 \%$ pure) were used as received. Commercial "anhydrous" ethanol was further dried (by the instructor) using activated $3 \AA$ molecular sieves. We purchased soybean oil (Liza) and coconut fat (QualiCôco) from a local supermarket.

\section{Preparation of ethyl carboxylate reference esters for GC analysis}

The instructor prepared ethyl undecanoate $\left(\mathrm{C}_{10} \mathrm{CO}_{2} \mathrm{Et}\right)$, ethyl 
dodecanoate $\left(\mathrm{C}_{11} \mathrm{CO}_{2} \mathrm{Et}\right)$, ethyl tridecanoate $\left(\mathrm{C}_{12} \mathrm{CO}_{2} \mathrm{Et}\right)$, and ethyl hexadecanoate $\left(\mathrm{C}_{15} \mathrm{CO}_{2} \mathrm{Et}\right)$ by reacting anhydrous ethanol with the appropriate carboxylic acid under reflux, in the presence of sulfuric acid catalyst. ${ }^{11}$ The alcohol was removed and the product was washed with cold aqueous $\mathrm{Na}_{2} \mathrm{CO}_{3}$ solution, then cold saturated $\mathrm{NaCl}$ solution, dried (granular anhydrous $\mathrm{MgSO}_{4}$ ), the solid filtered and the ester fractionally distilled under reduced pressure.

\section{Microwave-assisted synthesis of biodiesel}

The students worked in groups of six (one group of seven). Each group carried out the synthesis of one type of $\mathrm{BD}$ according to the procedure described elsewhere. ${ }^{11}$ Briefly, the students introduced $50 \mathrm{~mL}$ of sodium ethoxide/anhydrous ethanol solution $(0.75 \mathrm{wt} \%$ ethoxide; dispensed by the instructor) and $20 \mathrm{~g}$ of either $\mathrm{CF}$ or $\mathrm{SO}$ into $150 \mathrm{~mL}$ glass flask equipped with a reflux condenser and protected with a drying tube. The mixture was inserted into the cavity of a Discover MW-oven (CEM) and was stirred and heated $(100 \mathrm{~W}$; ethanol reflux) for $15 \mathrm{~min}$ (total energy consumed $=90 \mathrm{~kJ})$. Ethanol removal (rotary evaporator; reduced pressure) resulted in phase separation. The students removed the lower phase (glycerol), and washed the resulting $\mathrm{BD}$ with cold, saturated $\mathrm{NaCl}$ solution $(25$ $\mathrm{mL}$ portions) until the aqueous phase was neutral. Each group of students transferred the resulting BD to an Erlenmeyer flask provided with stopper, added granular anhydrous $\mathrm{MgSO}_{4}$, gave the flask to the instructor who kept it overnight, and then separated the BD sample by filtration (PTFE $0.45 \mu$ filtration membrane).

\section{Sample analysis by GC/MS}

The instructor carried out these analyses using Shimadzu QP 2010 Ultra gas chromatograph coupled to a single quadrupole mass spectrometer detector equipped with an electron ionization ion source (50 eV, range: 50 to $320 \mathrm{~m} / \mathrm{z}$, solvent delay: $3.5 \mathrm{~min}$ ), and using helium as carried gas $(1.43 \mathrm{ml} / \mathrm{min})$. We used Rtx-5MS column $(30 \mathrm{~m} \times 0.25$ $\mathrm{mm}, 0.25 \mu \mathrm{m}$ ) and the following temperatures: injection block, $250^{\circ} \mathrm{C}$; ion source, $260{ }^{\circ} \mathrm{C}$; GC/MS interface module: $280{ }^{\circ} \mathrm{C}$. The instructor diluted the BD samples with ethyl acetate $(1: 2000 \mathrm{v} / \mathrm{v})$ and injected $(1 \mu \mathrm{L})$ using the following temperature programing: $5 \mathrm{~min}$ at 120 ${ }^{\circ} \mathrm{C}$; increase to $240{ }^{\circ} \mathrm{C}$ at $8{ }^{\circ} \mathrm{C} /$ minute; $8 \mathrm{~min}$ at $240{ }^{\circ} \mathrm{C}$. Identification of the peaks was based on comparison of their mass spectra with a commercial database ${ }^{26}$ and by comparison with (authentic) reference esters $\mathrm{C}_{10} \mathrm{CO}_{2}$ Et and $\mathrm{C}_{12} \mathrm{CO}_{2}$ Et.

\section{Hazards}

There are no significant hazards in this experiment. Ethanol is flammable, and sodium ethoxide/ethanol is hazardous if ingested or absorbed through skin contact. Good laboratory practices should be followed; wearing of laboratory coat and using protective eyewear is mandatory. Solvents and solutions should be handled in a fume hood.

\section{RESULTS AND DISCUSSION}

This project requires a total of eight hours, divided over 3 weeks. One week before starting the project, the students conducted a literature survey on methods/mechanism of transesterification of oils and fats, analysis of biofuels, and heating by MW.

\section{Step 1: Transesterification of CF and SO}

In the first step of the project ( $3 h$ ), each student group performed the transesterification reaction and gave the instructor their BD sample. During this period, we discussed the advantage of using MW heating. Conventional, i.e., convection heating is rather slow and relatively inefficient method for transferring energy into a reaction mixture because it depends on convection currents and the thermal conductivity of the medium. On the other hand, MW irradiation produces efficient internal heating by direct coupling of MW-energy with the molecules present in solution. ${ }^{27} \mathrm{MW}$-assisted transesterification is efficient because of the medium inherent high "dielectric loss". Qualitatively, we describe the latter as the loss of energy that goes into heating when a rotating dipolar species is irradiated with an alternating electric field of the appropriate frequency. This property is parameterized in terms of either the loss angle $(\delta)$ or the corresponding loss tangent $(\tan \delta)$. Large $\tan \delta$ mean efficient conversion of MW energy into heat; ethanol is superior than water; $\tan \delta=0.941$, and 0.123 , respectively. ${ }^{28}$ This efficient heating generates transient "hot spots" in the reaction mixture where the temperature is much higher that the b.p. of ethanol, with concomitant increase in the transesterification reaction rate..$^{29,30}$ We stressed that household MW ovens should not be used for heating (of reactions) in the laboratory (for safety reasons).

\section{Step 2: GS/MS analysis of BD samples}

In the second period of the project $(3 h)$, we demonstrated the analysis of the students' BD samples by GC/MS. Subsequently, we gave them the results and went to the classroom for further discussion. Examining the results, the students promptly noticed the difference between the fatty acid composition of $\mathrm{CF}_{\mathrm{BD}}$ and $\mathrm{SO}_{\mathrm{BD}}$ (Figure 1). The column employed separates fatty acid ethyl esters (FAEEs) according to their boiling points, i.e., smaller retention times correspond to shorter-chain FAEEs. Consequently, $\mathrm{CF}_{\mathrm{BD}}$ is much richer than $\mathrm{SO}_{\mathrm{BD}}$ in short-chain FAEEs.

With regard to qualitative analysis of these BDs, the students suggested adding internal references (authentic esters). Most naturally occurring fatty acids (up to hexadecanoic acid) are bio-synthesized by addition of two carbon units to acetyl coenzyme A from malonyl coenzyme A (with loss of $\mathrm{CO}_{2}$ ); double bonds are introduced into the chain by fatty acyl-coenzyme A desaturase. ${ }^{31}$ Therefore, the students suggested the use of an ethyl ester with an odd number of carbon atoms $;{ }^{32}$ we offered $\mathrm{C}_{10} \mathrm{CO}_{2} \mathrm{Et}$ and $\mathrm{C}_{12} \mathrm{CO}_{2} \mathrm{Et}$. We informed the students that we would add these two esters to their samples, repeat the GC/MS analysis, and send them the results for discussion in the classroom.

\section{Step 3: Discussion of the results}

The project ended with discussion of the results in the classroom; it required $2 h$. Figure 2 shows the chromatograms of $\mathrm{CF}_{\mathrm{BD}}$ and $\mathrm{SO}_{\mathrm{BD}}$ with the above-mentioned internal references added. The peaks of these esters have different retention times from those of the synthesized $\mathrm{BD}$ samples, hence can be used for qualitative analysis of the BDs. For example, in Figure $2 \mathrm{~A},\left(\mathrm{C}_{11} \mathrm{CO}_{2} \mathrm{Et}\right.$, peak 3$)$ comes after $\left(\mathrm{C}_{10} \mathrm{CO}_{2} \mathrm{Et}\right.$, peak 9$)$ whereas $\left(\mathrm{C}_{13} \mathrm{CO}_{2} \mathrm{Et}\right.$, peak 4$)$ and $\left(\mathrm{C}_{15} \mathrm{CO}_{2} \mathrm{Et}\right.$, peak 5) come in sequence after $\left(\mathrm{C}_{12} \mathrm{CO}_{2} \mathrm{Et}\right.$, peak 10$)$. The peaks corresponding to the FAEEs higher than $\left(\mathrm{C}_{15} \mathrm{CO}_{2} \mathrm{Et}\right)$ can be identified from the retention time order given in literature. ${ }^{33,34}$ We gave the students the concentrations of the internal references in each sample (v\%) plus a table of the CG peak areas, and asked them to calculate the compositions of $\mathrm{CF}_{\mathrm{BD}}$ and $\mathrm{SO}_{\mathrm{BD}}$, assuming response factor of unity of all components.

For systems whose composition/history is unknown the internal references approach cannot be used. We then discussed the concept of hyphenated-techniques, where we combine two different analytical techniques. Examples are gas or liquid chromatography with a method 


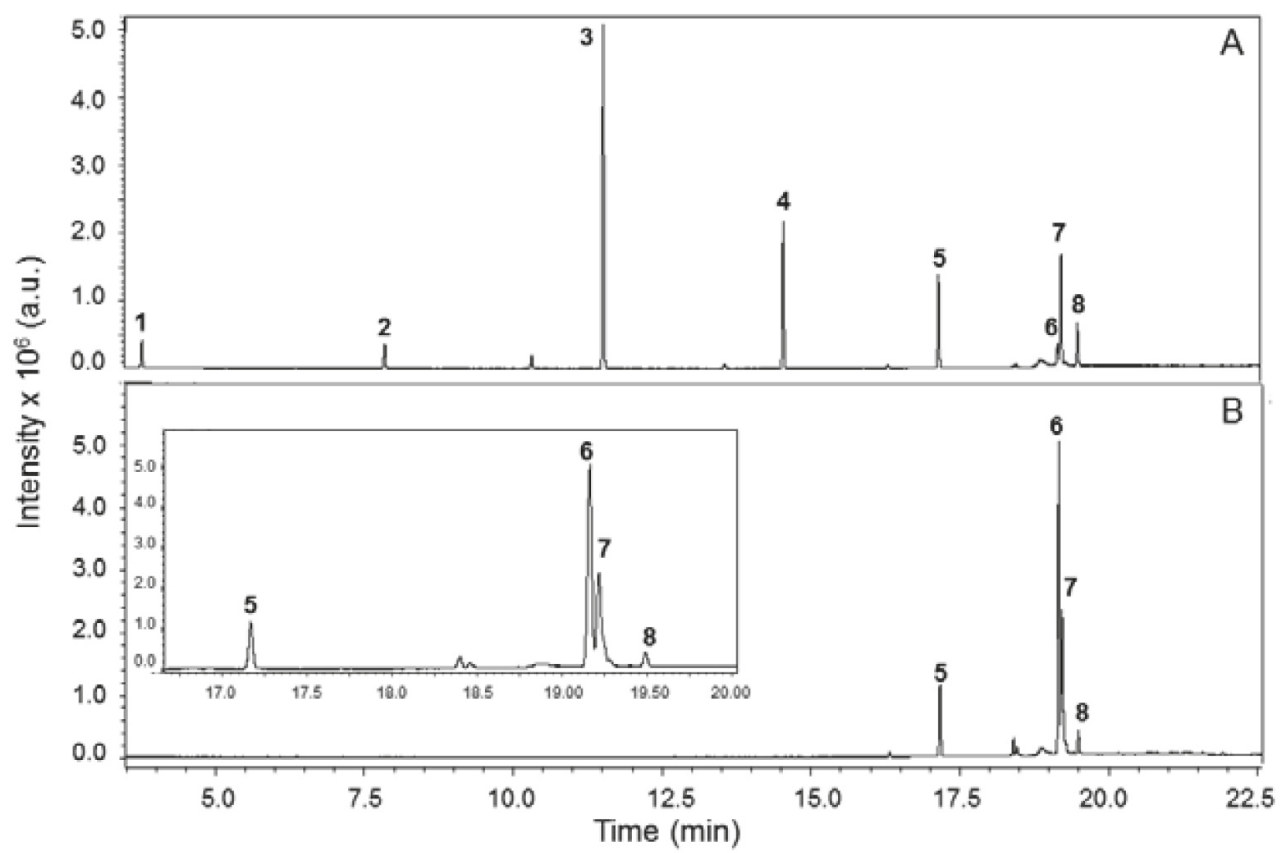

Figure 1. Gas chromatograms of biodiesel samples obtained by $M W$-assisted, base-catalyzed transesterification of CF (part A) and SO (part B). See legend of Figure 2 for ester peak assignment

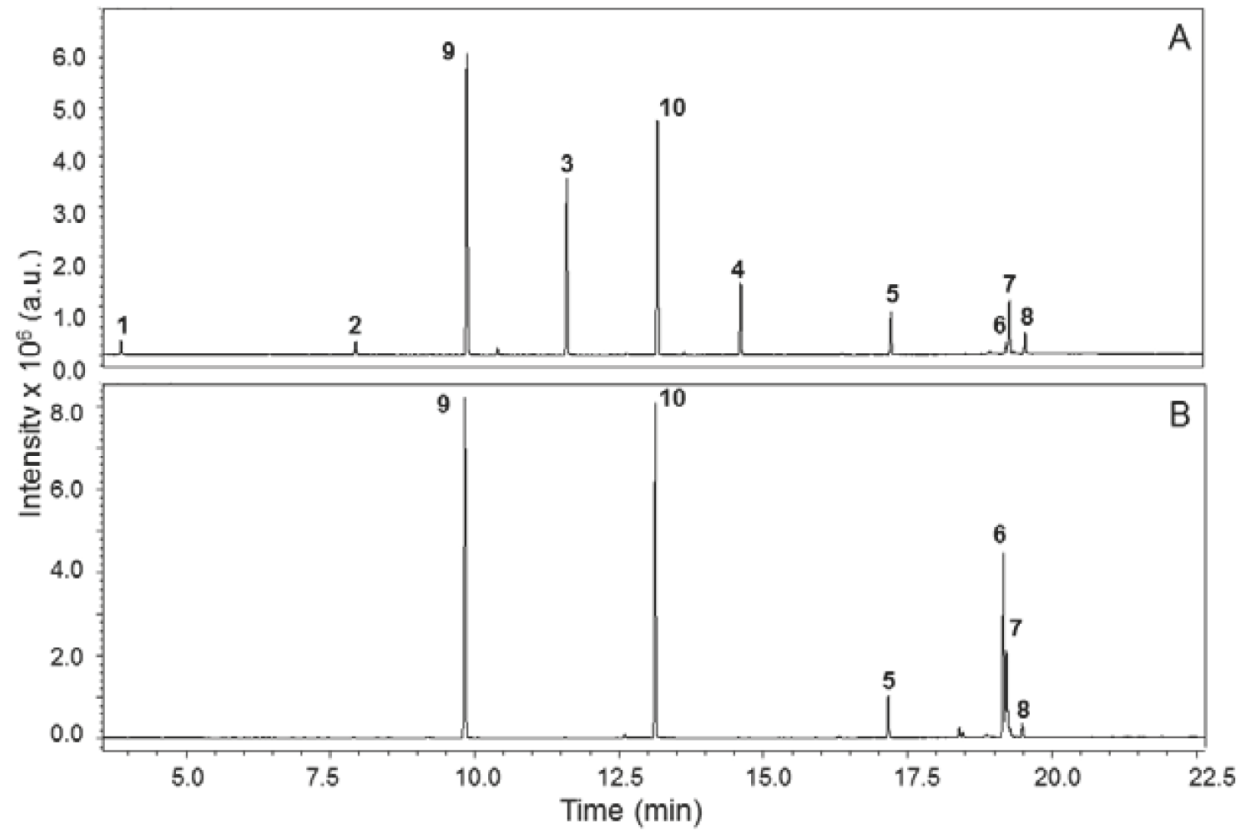

Figure 2. Gas chromatograms of $\mathrm{CF}_{B D}$ (part A) and $\mathrm{SO}_{B D}$ (part B) containing $\left(C_{10} \mathrm{CO}_{2}\right.$ Et, peak 9) and $\left(C_{12} \mathrm{CO}_{2}\right.$ Et, peak 10) as internal references. Peaks 1 , 2, 3, 4, 5, 6, 7, 8 refer to the ethyl esters of octanoic, decanoic, dodecanoic, tetradecanoic, hexadecanoic, linoleic, oleic, and octadecanoic acid, respectively

that gives structural information, FTIR, NMR, or MS..$^{24,25}$ A section of the GC/MS of both BD samples as well as of the authentic samples were projected on the screen and the students were asked to analyze the results. Figure 3 shows the $\mathrm{MS}$ of $\mathrm{C}_{11} \mathrm{CO}_{2} \mathrm{Et}$ and the peak designated as ethyl dodecanoate in $\mathrm{CF}_{\mathrm{BD}}$, whereas Figure 4 shows the $\mathrm{MS}$ of $\mathrm{C}_{15} \mathrm{CO}_{2} \mathrm{Et}$ and the peak designated as ethyl hexadecanoate in $\mathrm{SO}_{\mathrm{BD}}$. Both Figures confirm the designation of these peaks as concluded previously from the use of internal references. The FAEEs compositions shown in Table 1 were calculated for the BD samples produced by one group from the results of $\mathrm{GC}$; they are not far from those reported for Nigerian $\mathrm{CF}_{\mathrm{BD}}{ }^{35}$ and Brazilian $\mathrm{SO}_{\mathrm{BD}} \cdot{ }^{36}$ From the applied point of view, the higher content of esters of saturated fatty acids mean than $\mathrm{CF}_{\mathrm{BD}}$ has a higher cetane number, hence is a better fuel than $\mathrm{SO}_{\mathrm{BD}}$.

\section{Students' performance in the quiz on the project}

We included questions on this project in the final exam of Chem1405. The students solved these questions in groups of two (one group of three). This part of the exam took 90 minutes and included four modules; each is related to the information from the previous one. We distributed the modules in sequence; gave them time to answer, and then collected the answer sheets before giving the next module. The following were the subjects/concepts of the modules: (1) Fundamental aspects of transesterification (structure of reaction intermediates; reaction yield; ethanol/water azeotrope; industrial production of ethanol), (2 and 3) GC analysis of BDs without and with internal standards, (4) analysis of BD samples using tandem 


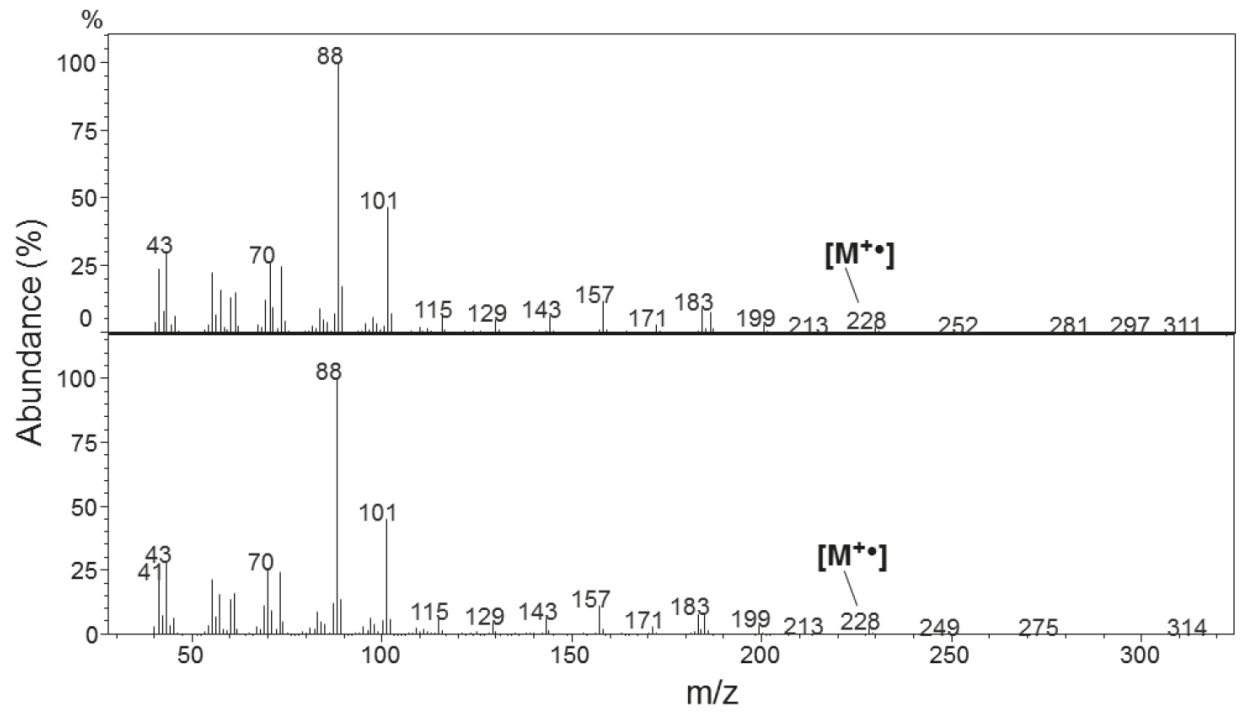

Figure 3. $\mathrm{MS}$ of (authentic) $\mathrm{C}_{11} \mathrm{CO}_{2}$ Et (part A) and peak 3 of Figure 2A, designated as ethyl dodecanoate (part B). The molecular ion is shown at $\mathrm{m} / \mathrm{z}=228.38$. The abundance \% of each peak refers to its intensity relative to that of the base peak at $\mathrm{m} / \mathrm{z}=88$. The latter corresponds to the so-called McLafferty peak due to the ion $\left(\mathrm{C}_{2} \mathrm{H}_{5} \mathrm{OC}\left(\mathrm{OH}^{+}\right)=\mathrm{CH}_{2}\right)$. The similarity of the spectra of parts A and B shows the correctness of the attribution of peak 3 of Figure $2 \mathrm{~A}$

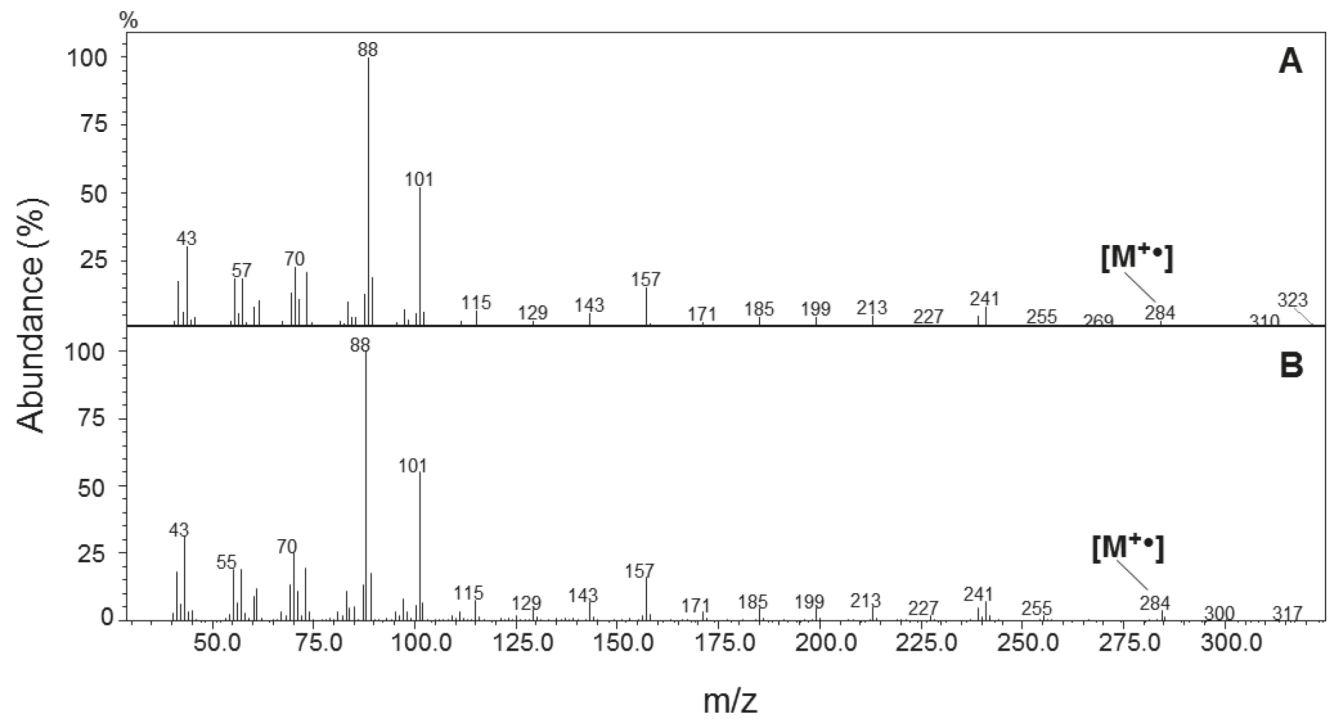

Figure 4. MS of (authentic) $\mathrm{C}_{15} \mathrm{CO}_{2}$ Et (part A) and peak 5 of Figure $2 B$, designated as ethyl palmitate (part B). The molecular ion is shown at $\mathrm{m} / z=284.48$. For definition of abundance \% see legend to Figure 3. The similarity of the spectra of parts $A$ and B shows the correctness of the attribution of peak 5 of Figure $2 B$

Table 1. Composition of BD samples derived from coconut fat and soybean oil ${ }^{a}$

\begin{tabular}{|c|c|c|c|c|c|c|c|}
\hline \multirow[t]{2}{*}{ Entry } & \multirow[t]{2}{*}{ Ethyl ester } & \multirow[t]{2}{*}{ Molecular Formula } & \multirow[t]{2}{*}{ Molar mass } & \multicolumn{2}{|c|}{$\begin{array}{l}\text { Retention time, min } \\
\text { Composition, } v \%\end{array}$} & \multicolumn{2}{|c|}{$\begin{array}{l}\text { Retention time, min } \\
\text { Composition, } \mathrm{v} \%\end{array}$} \\
\hline & & & & $\mathrm{BD}$, Coconut fat & & BD, Soybea & \\
\hline 1 & Octanoate & $\mathrm{C}_{10} \mathrm{H}_{20} \mathrm{O}_{2}$ & 172.27 & 3.85 & 3.28 & & \\
\hline 2 & Decanoate & $\mathrm{C}_{12} \mathrm{H}_{24} \mathrm{O}_{2}$ & 200.32 & 7.92 & 3.17 & & \\
\hline 3 & Dodecanoate & $\mathrm{C}_{14} \mathrm{H}_{28} \mathrm{O}_{2}$ & 228.38 & 11.56 & 44.31 & & \\
\hline 4 & Tetradecanoate & $\mathrm{C}_{16} \mathrm{H}_{32} \mathrm{O}_{2}$ & 256.43 & 14.62 & 17.86 & & \\
\hline 5 & Hexadecanoate & $\mathrm{C}_{18} \mathrm{H}_{36} \mathrm{O}_{2}$ & 284.48 & 17.17 & 10.56 & 17.17 & 12.32 \\
\hline 6 & Linoleate & $\mathrm{C}_{20} \mathrm{H}_{36} \mathrm{O}_{2}$ & 308.51 & 19.15 & 2.35 & 19.16 & 55.76 \\
\hline 7 & Oleate & $\mathrm{C}_{20} \mathrm{H}_{38} \mathrm{O}_{2}$ & 310.52 & 19.21 & 13.31 & 19.22 & 26.87 \\
\hline 8 & Octadecanoate & $\mathrm{C}_{20} \mathrm{H}_{40} \mathrm{O}_{2}$ & 312.54 & 19.49 & 5.15 & 19.49 & 3.85 \\
\hline
\end{tabular}

${ }^{a}$ Peak assignment is based on $\mathrm{m} / \mathrm{z}$ of the molecular ion peak. FAEE composition in $\mathrm{v} \%$ was calculated from CG analysis. 
techniques. We list the questions given and the performance of the students in Supporting Information. As shown, their performance was satisfactory, with the majority giving answers that are correct or partially correct.

\section{CONCLUSIONS}

We used a project on the synthesis and analysis of BDs from fatty materials to introduce "hands-on" approach to chemical transformation and product analysis. In each step of the project, we discussed the concept involved, e.g., transesterification as an example of acyl-transfer reactions; unconventional heating by MW irradiation; strategies for qualitative and quantitative analysis of mixtures using single- (GC) and hyphenated techniques (GC/MS). BD is a subject of tremendous socio-economic relevance; the experiments are lowcost and safe. This project can be carried out with less sophisticated equipment because BD can be prepared by conventional (i.e., convection) heating; GC alone plus use of the internal references indicated and access to commercial databases turn qualitative and quantitative analysis of BFs feasible. The performance of the students in the quiz showed an important outcome of this project: linking theory to experimental.

\section{SUPPLEMENTARY MATERIAL}

In the supplementary material we give comments for the Instructor and the students' performance in the quiz on this project. They can be freely accessed at http://quimicanova.sbq.org.br in PDF format.

\section{ACKNOWLEDGEMENTS}

We are grateful to the students who participated in this project. We thank C. Guizzo for the graphical abstract, Prof. M. J. Kato for helpful comments, São Paulo Research Foundation, FAPESP, for financial support and fellowships via grants 2013/18008-8, 2014/221364, 2014/50316-7. O. A. El Seoud thanks the National Research Council, CNPq for research productivity grant 307022/2014-5; L. F. Yamaguchi thanks USP Research Pro-Rectory for support.

\section{REFERENCES}

1. Tri-State biodiesel Biodiesel: definition and benefits, available at http:// www.tristatebiodiesel.com/download/biodieselbenefits.pdf, accessed on June 2018.

2. Biodiesel Education Network, available at http://biodiesel.org/what-isbiodiesel/biodiesel-faq's, accessed on June 2018.

3. Alternative fuels data center, available at https://www.afdc.energy.gov/ fuels/biodiesel_blends.html, accessed on June 2018.

4. . Resolução CNPE 23/2017.

5. https://www.statista.com/statistics/271472/biodiesel-production-inselected-countries/, accessed on June 2018.

6. Education for sustainable development, available at http://www. unesco.org/new/en/education/themes/leading-the-international-agenda/ education-for-sustainable-development/, accessed on June 2018.
7. Bendall, S.; Birdsall-Wilson, M.; Jenkins, R.; Chew, Y. M. J.; Chuck, C. J.; J. Chem. Educ. 2015, 92, 683.

8. King, A. G.; Wright, M. W.; J. Chem. Educ. 2007, 84, 202.

9. De La Rosa, P.; Azurin, K. A.; Page, M. F. Z.; J. Chem. Educ. 2014, 91, 1689.

10. Yang, J.; Xu, C.; Li, B.; Ren, G.; Wang, L.; J. Chem. Educ. 2013, 90, 1362.

11. Novaki, L. P.; Chinelatto, A. M.; d'Almeida e Silva, M. J. L.; Brotero, P. P.; El Seoud, O. A.; J. Lab. Chem. Educ. 2016, 4, 38.

12. Goldstein, S. W.; J. Chem. Educ. 2014, 91, 1693.

13. Schuchard, U.; Serchelia, R.; Vargas, R. M.; J. Braz. Chem. Soc. 1998, 9, 199.

14. Demirbas, A.; Energy Convers. Manage. 2009, 50, 14.

15. Venkateswarulu, T. C.; Raviteja, C. V.; Prabhaker, K. V.; Babu, D. J.; A. Reddy, A. R.; Indira, M.; Venkatanarayana, A.; Int. J. ChemTech Res. 2014, 6, 2568.

16. Knothe, G.; Dunn, R. O.; Bagby, M. O.; ACS Symp. Ser. 1997, 666, 172.

17. Ejaz, M. S.; Younis, J.; Renewable Sustainable Energy Rev. 2008, 12, 2484.

18. Knothe, G.; JAOCS 2006, 83, 823.

19. US import data: 10 Countries with largest soybean production, available at http://www.worldatlas.com/articles/world-leaders-in-soya-soybeanproduction-by-country.html_accessed on June 2018.

20. http://www.indexmundi.com/agriculture/?commodity=soybean-oil, accessed on June 2018; http://www.factfish.com/statistic/coconuts, $\% 20$ production\%20quantity, accessed on June 2018.

21. Orsavova, J.; Misurcova, L.; Ambrozova, J. V.; Vicha, R.; Mlcek, J.; Int. J. Mol. Sci. 2015, 16, 12871.

22. Typical fatty-acid compositions of some common fats, available at http:// web.pdx.edu/ wamserc/C336S12/fat.pdf, accessed on June 2018.

23. Shahidi, F.; Wanasundara, U. N. In Food lipids: Chemistry, nutrition and biotechnology, $2^{\text {nd }}$ ed.; Akoh, C. C., Min, D. B., eds.; Marcel Dekker: New York, 2002, chap. 14, pp. 387-406.

24. Prasain, J. K.; Tandem Mass Spectroscopy: Applications and Principles, InTech publishing, Rijeka, 2012.

25. Phalke, P.; Kavade, S.; Int. J. Chem. Studies 2013, 1, 157.

26. McLafferty, F. W.; Wiley registry of mass spectral data, upgrade, $9^{\text {th }}$ ed., Wiley: New York, 2009.

27. Kappe, C. O.; Chem. Soc. Rev. 2008, 37, 1127.

28. Kappe, C. O.; Angew. Chem., Int. Ed. 2004, 43, 6250.

29. Reimbert, C. G.; Minzoni, A. A.; Smyth, N. F.; IMA J. Appl. Math. 1996, $57,165$.

30. De la Hoz, A.; Díaz-Ortiz, A.; Moreno, A.; Chem. Soc. Rev. 2005, 34, 164.

31. Nelson, D. L.; Cox, M. M.; Lehninger principles of biochemistry, Worth Publishers: New York, 2000, pp. 770-817.

32. Diedrich, M.; Henschel, K. P.; Die Nahrung 1990, 34, 935.

33. Kulig, C. C.; Beresford, T. P.; Everson, G. T.; J. Lab. Clin. Med. 2006, 147, 133.

34. Bernhardt, T. G.; Cannistraro, P. A.; Bird, D. A.; Doyle, K. M.; Laposta. M.; J. Chromatogr. B 1996, 675, 189.

35. Alamu, O. J.; Dehinbo, O; Sulaiman, A. M.; Leonardo J. Sci. 2010, 16, 95.

36. Ferrari, R. A.; Oliveira, V. S.; Scabio, A.; Quim. Nova 2005, 28, 19. 